\title{
Environmental Assessment of Bio-Oil Transformation from Thistle in the Italian Context: An LCA Study
}

\author{
Samuele TORTOIOLI ${ }^{1}$, Luisa PAOLOTTI ${ }^{2}$, Francesco ROMAGNOLI $^{3 *}$, Antonio BOGGIA ${ }^{4}$, \\ Lucia ROCCHI ${ }^{5}$
}
1, 2, 4, 5 Department of Agricultural, Food and Environmental Sciences, University of Perugia, Borgo XX Giugno 74, 06121 Perugia, Italy

${ }^{3}$ Institute of Energy Systems and Environment, Riga Technical University, Azenes iela 12/1, Riga, LV-1048, Latvia

\begin{abstract}
The present study is a cradle-to-gate Life Cycle Assessment of a hypothetical production process of rigid polyurethane foam obtained from thistle seed oil, grown on the marginal soils of the Umbria region, Italy. Thistle is a particularly rustic crop, suitable for difficult soil and climatic conditions that allow its cultivation in the Mediterranean area on marginal lands and with only the water supply of the autumn-spring rains. Life Cycle Inventory was built on up-to-date inventory for thistle production, while experimental data for polyol and synthesis were obtained from literature, with reference to a pilot scale reactor. Energy recovery of lignocellulosic biomass and sensitivity analysis were also included in the study. Life Cycle Assessment was performed using SimaPro 9.0 and impacts were evaluated with the Impact 2000+ method. Results show the overall impact of thistle oil including its final use for the production of polyurethane foam, and underline the important contribution as environmental benefit of the use of biomass leftovers in the agricultural phase. Moreover, results show that the major impacts of the rigid polyurethane foam production process were related to the synthesis of the foam itself. Among the previous phases constituting the process of synthesis of the polyol, the most impactful one was the cultivation; the oil processing stage, on the other hand, had a small global impact. The synthesis of the foam, taken individually, generated a greater impact than the entire synthesis process of the vegetable polyol starting from the cultivation of thistle.
\end{abstract}

Keywords - Environment assessment; life cycle assessment; polyols; polyurethane; thistle oil

\section{INTRODUCTION}

Over the past decade, EU has addressed important efforts to the transition to carbon free economy with an emphasis on the reduction of the use of fossil-based feedstock. This commitment has been revealed within the definition of the ambitious targets of the EU "Green deal", in which the Bioeconomy plays a key role.

Under this important direction, several policy strategies, road maps, strategical partnerships and cooperation have been promoted to strengthening and making more sustainable the Bioeconomy transition [1]. Among the others, bioplastic production represents a strategic sector for the EU Bioeconomy.

* Corresponding author.

E-mail address: Francesco.romagnoli@rtu.lv 
Direct plastic pollution is a global concern [2], but only one of the environmental problems caused by plastic [3]. Bioplastics are used as an alternative material to petroleum-based plastics, mainly in the form of consumer goods and packaging. However, the ability of bioplastics to reduce environmental impacts compared to traditional ones is still debated, due to the use of raw materials from agriculture, which can be a direct cause of many other negative environmental effects [3].

The raw materials most used in the production of bioplastic include vegetable oils, polysaccharides (mainly cellulose and starch), wood and proteins [4]. In particular, vegetable oils represent a promising path for the production of biopolymers, thanks to their ready availability, intrinsic biodegradability and low toxicity [5]. Polymers from vegetable oils range from linear thermoplastics to cross-linked thermosets, from soft and flexible rubbers to hard and ductile plastics; some vegetable oil-based polymers show comparable or better properties than petroleum-based polymers [6].

Rigid polyurethane foams can be synthesized from vegetable oils, which have been considered good substitutes for the production of polyols [7]. Recently, studies on these new bio-based materials have intensified, considering different raw oils, depending on the geographical context. Tan et al. [8] synthesized polyurethane foams based on soybean oil, observing a foam density $17 \%$ higher than the control foam, an initial thermal conductivity comparable to traditional ones and a greater compressive strength. At the same time, an accelerated aging and a higher level of degradation were detected [8]. Fridrihsone et al. [9] found that the production of rigid polyurethane foam from rapeseed polyols allows a reduction of GHG emissions between 35 and $75 \%$ of GHG. In his review on castor oil and its uses, Mubofu [10] underlines an increase in its use for the production of polyurethane. Although the commercial interest for rigid Polyurethane from polyols, there is still a lack of studies about environmental impact of natural oil-based polyols [9].

From the performed literature review, the centrality of the bio-based industry at European level has been highlighted; at the same time, there is a need to explore the overall environmental feasibility of novel bio-based products, especially of bio-oil and further refined products, from a cradle-to-grave perspective. For this reason, the application of a quantitative method able to evaluate the environmental performance of the product system under a holistic view is essential.

Within the frame of the EU Green Deal, the transition to a sustainable bio-economy should be properly assessed, exploring the potential use of bio-based resources. In this light, an important emphasis is also put on the production of bio-based chemicals. This evaluation is essential in order to avoid concerns on the uncontrolled increase of agricultural land creating even a rebound effect on the environmental impact.

Thus, the use of the Life Cycle Assessment (LCA) is essential both for the evaluation of the overall impact, aiming to exclude the shift of any environmental burdens in the considered product system, and to better evaluate the potential benefits of the use of by-products and/or biological wastes as potential avoided impact, according to the guidelines in the ISO 14044:2006 (i.e. system expansion approach).

Several studies have already been proposed on different type of feedstock to produce oil [11], [12] but there is still a lack on study performed for local or regional conditions.

The present work tries to fill the gap, through the realization of a 'cradle-to-gate' LCA study of polyurethane foams made with thistle oil in Umbria (Central Italy). The thistle (Cynara cardunculus) is a rustic plant, originating from the Mediterranean basin, suitable for difficult soil and climatic conditions, even on marginal lands and with only the water supply of the autumn-spring rains. In addition to the use of the aerial parts as raw material for the production of energy and food concentrates for livestock, the oil extracted from the achenes 
can constitute a starting element for the production of biodiesel and biopolymers [13]. The model is based on an in-depth and up-to-date agricultural practice typical of the Mediterranean area. The polyol production from thistle oil for polyurethane foam has been supposed to be synthetized by amidization with diethanolamine. The main information about this process has been collected though a literature review.

In particular, this LCA aims to evaluate the overall environmental hotspots from the transformation process of thistle oil (extracted within central Italy context) to its end use including polyol synthesis for rigid polyurethane foam production. The benefits of using biomass leftovers resulting from the agricultural phase for energy purposes were also considered.

\section{MethodS}

This study was performed with the support of the LCA methodology as standardized procedure able to assess the environmental impacts of the proposed product system, including the specific unit processes in a cradle-to-gate approach. The reference ISO 14040 and 14044:2006 Standards [14], [15] were selected.

SimaPro 9.0 [16] software developed by Pré Consultants and Ecoinvent 3.0 [17] supported the data processing for the creation of the LCA model and the overall environmental impact were evaluated using IMPACT 2002+ method [18].

\section{GoAL AND SCOPE DEFINITION}

The aim of this study is to evaluate both the effect of transformation of thistle oil to polyol to synthetize rigid Polyurethane foam and the valorization of lignocellulosic biomass from collection of remains in the agricultural phase, for energy recovery. The geographical boundaries can be set with reference to middle Italy context.

According to the ISO Standards 14044, the system is considering a system expansion in order to avoid allocation and to better evaluate the beneficial contribution from the use of byproducts. In specific, lignocellulose leftovers from thistle harvesting are used for production of biogas and further use in a cogeneration unit, providing an avoided environmental burden (see Fig. 1). In the section of the inventory the overall avoided impact, assumptions are described. The use of thistle oil seed cake and glycerine from oil refining as by-products are not considered at this stage of the study, and thus considered not considered in system expansions including avoided impacts.

\subsection{Functional Unit and System Boundary}

The functional unit (FU) established for carrying out this study is $1 \mathrm{~kg}$ of rigid polyurethane foam; thus, all the inflows and outflows entering or leaving the system have been referred to this unit. The system boundary referred to the FU is presented in Fig. 1. 


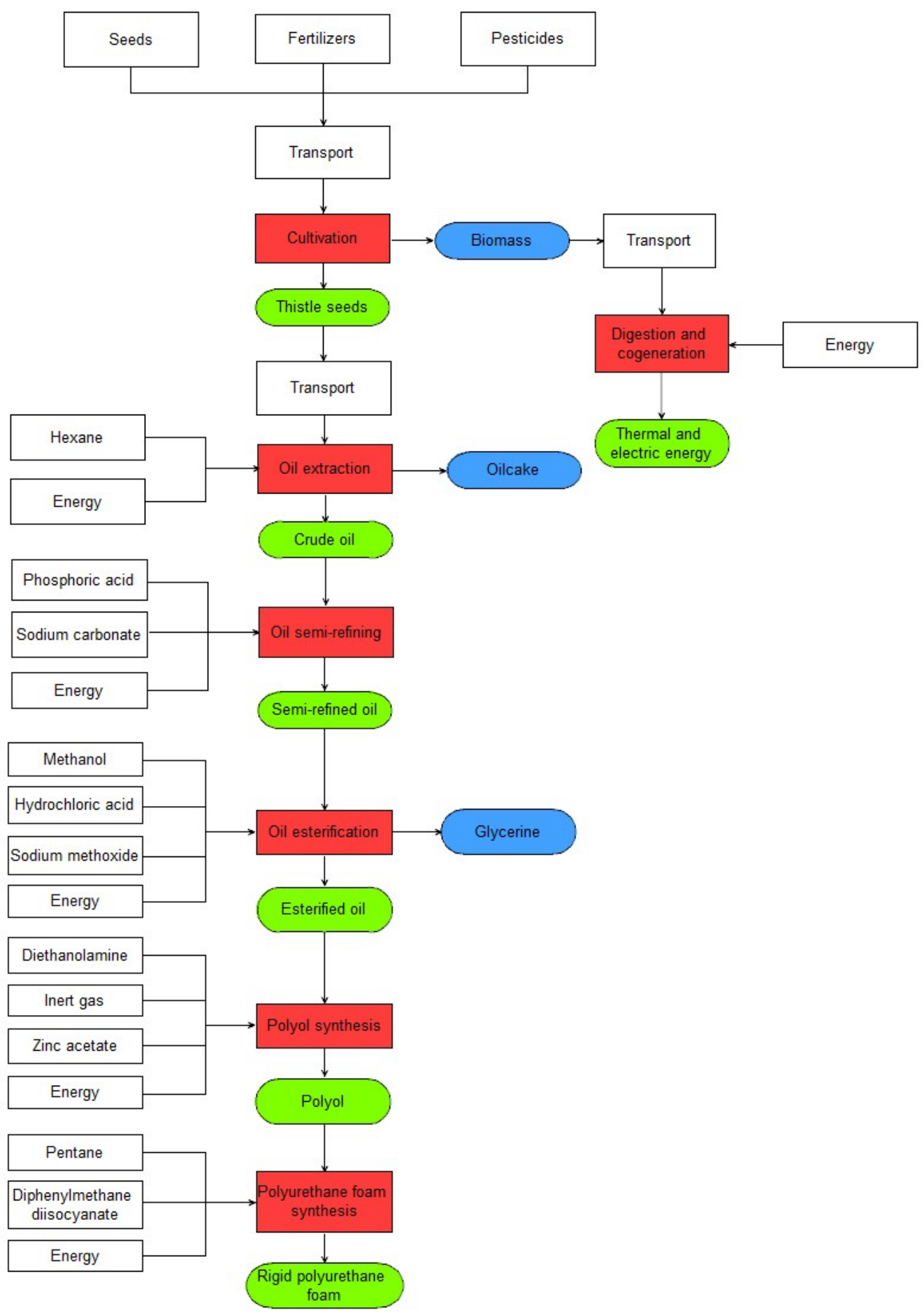

Fig. 1. System boundaries of rigid polyurethane foam production from thistle oil. 
With reference to the scheme reported in Fig. 1, the overall investigated LCA system considers 6 main unit processes: the thistle cultivation and harvesting, the thistle oil extraction, the thistle oil refining, the esterification of the thistle oil, the synthesis of the polyol, and the synthesis of the rigid polyurethane foam. As previously mentioned at this stage of the study the valorisation of the by-product has been considered only for the lignocellulosic leftovers.

\subsection{Quality of the Input Data}

The importance of having primary data is crucial for LCA studies focused on bio-based feedstock. This is essential to have a consistent inclusion of all upstream processes for the feedstock production. For this study, part of the inventory data is based on the project FORTE [19] even if only in its preliminary stage, mostly addressed to the thistle cultivation and harvesting.

More in specific, this project foresees the cooperation of several private companies and institutes with the aim to apply bioeconomy principle and approach to develop an agroindustrial chain in a middle Italy Region (i.e. Umbria), which allows the synergic use of agricultural resources and related co-products from cultivation of low input oil seeds, in order to obtain a portfolio of value added products and applications in different sectors.

At this stage of the study just preliminary information were useful to be used for characterizing the background processes. The main information obtained from one project partners were related to the agricultural sector of thistle cultivating system up to the harvested biomass - e.g. assumed biomass yields, seeding, ploughing, agricultural operations for biomass movement and application of fertilizers and plant protection products.

The information for the definition of the inventory related to the oil extraction, synthesis of polyol from thistle oil and rigid polyurethane have been defined from data from literature and are presented in the inventory part.

In this study, the transportation assumption (i.e. distance and means of transport) and the selection of the electricity matrix were adapted to the Italian context using the already existing Ecoinvent 3.0 [17] database available in the software Simapro used for this study. In addition, other input data necessary to finalize the inventory information were selected from Ecoinvent 3.0 database [17].

\subsection{Impact Categories and Impact Assessment Method}

For this specific case the selected Life Cycle Impact Assessment method was the end-point - based method IMPACT 2002+, for which final single score results can be presented with 4 main damage categories - i.e. Human Health, Biodiversity, Use of Resources, and Climate Change. The selection of this impact assessment method was mainly connected to have climate change as standing alone damage category.

IMPACT 2002+, acronym of IMPact Assessment of Chemical Toxics, was developed by Swiss Federal Institute of Technology - Lausanne (EPFL). In IMPACT2002+ the midpoint impact category level consists of 15 environmental issues (midpoint indicators) namely: Human toxicity (carcinogens/non-carcinogens), Respiratory effects, Ionizing radiation, Ozone layer depletion, Photochemical oxidation, Aquatic and Terrestrial Ecotoxicity, Aquatic Acidification and Eutrophication, Terrestrial acidification, Land Occupation, Global warming, Non-renewable energy, Mineral Extraction. 


\section{Life CyCLE InVENTORY ANALYSIS}

\subsection{The Production Process}

The production process of polyurethane foam is described in Fig. 1 and begins with the thistle cultivation phase; the grain, after being separated from the biomass and collected, is transported to a hypothetical processing site where the second phase starts: the extraction of the oil. The seeds are cleaned of impurities and then finely crushed and immersed in a solvent bath of hexane. After the contact time has elapsed, the solvent is evaporated by raising the bath temperature up to $150{ }^{\circ} \mathrm{C}$ and condensed to be reused later. Once evaporation is complete, the oil is filtered and sent to the next phase; the cake obtained as a by-product can be used in other processes [20].

At this point, the oil enters the third phase of the process: semi-refining. Here, the acidity of the oil, due to the presence of free fatty acids, is neutralized by means of a treatment with phosphoric acid solution and a water-base mixture of sodium carbonate. Free fatty acids are thus bound from the base, forming sodium salts and then saponifying. The soaps precipitate and are removed by water. The obtained oil, neutralized, is semi-refined and ready for the next phase of esterification [20].

In the esterification process, a reaction takes place between a triglyceride and an alcohol, which leads to the formation of a mixture of fatty acids and glycerine. In a first esterification stage, methanol is used together with hydrochloric acid as catalyst. In the second stage methanol and sodium methoxide as a basic catalyst are used.

The next step is the synthesis of the polyol starting from the esterified oil. In this case study it is made by amidization with diethanolamine. The reaction is carried out in a reactor equipped with a mechanical stirrer, a thermometer, a cooling device and an inlet pipe for the inert gas [9]. The oil is heated to $140 \pm 5{ }^{\circ} \mathrm{C}$, then $0.15 \%$ of zinc acetate is added as a catalyst, and during the following 15 minutes the pre-heated diethanolamine is added to $70{ }^{\circ} \mathrm{C}$. The reaction continues for 4-5 hours until the result is tested for solubility of the product in ethanol; if the polyol solubilizes, the amidization reaction is complete [9].

The last phase of this process is the synthesis of rigid polyurethane foam; the synthesis occurs through a chemical reaction between two basic components, the polyol and the diphenylmethane diisocyanate, and a low boiling point expanding agent, pentane. The basic materials react directly to mixing and build a polymer matrix: polyurethane. The heat released in this reaction causes the evaporation of the expanding agent and the foaming process of the polymer matrix [21].

Contemporary, the process of thistle residual biomass conversion in biogas was analysed. The transformation of biomass into biogas takes place through anaerobic digestion, a very complex process operated by different groups of bacteria that act in series. It is hypothesized that biogas is used to power a cogeneration plant. A part of the gas obtained feeds a boiler for the production of thermal energy while another percentage of gas feeds a turbine for the production of electricity.

\subsection{Data Assumptions, Data Sources and Allocation Procedure}

Concerning the first phase related to thistle cultivation, all the main data were provided by Novamont, an Italian company, international leader in the bioplastics sector and in the development of biochemical. The company has been studying the culture for years, for obtaining oil to produce bioplastics. The cultivation data do not refer to the productions obtained in the Umbrian territory, in which the crop has just been introduced, but to a cultivation developed in northwestern Sardinia, which is however a Mediterranean area as 
well as Umbria region is. In that area, marginal lands can easily be destined for this crop, thanks to its characteristics of resistance and adaptation to poor and arid soils, otherwise difficult to use. The reference cultivation area was one hectare. According to Novamont experimentation, the yield of the crop is $1.5 \mathrm{ton} / \mathrm{ha}$ of achenes and $15 \mathrm{ton} / \mathrm{ha}$ of biomass. The main operations considered were ploughing, harrowing, sowing, fertilizing, weeding and harvesting. Since the cultivation lasts about 6 years, the operations that are carried out only in the first year of cultivation (ploughing, sowing and weeding) were counted on $1 / 6$ of the surface, to avoid an overestimation of their impact; only the harrowing, which is carried out in the first and second year, has been counted for $2 / 6$ of the surface. The fertilizers used during the 6 years cultivation were considered (Urea, Diamonium phosphate, Nitrogen, Compost). As for plant protection products, the use of a common herbicide, containing $455 \mathrm{~g} / \mathrm{L}$ of Pendimetalin, has been hypothesized; this element was also counted $1 / 6$ for the previous reasons. Among the inputs of cultivation, the seed was not considered because the thistle is not present in the software databases and the adaptation of other crops would have involved too complex calculations. For counting the transport processes, a distance of $25 \mathrm{~km}$ from inputs supplier to the farm was hypothesized.

In relation to emissions coming from the cultivation phase, nitrous oxide emissions were calculated using Global Nitrous Oxide Calculator [22], an online tool that returns the output data after entering information on the environment, agronomic management and geographical location; ammonia emissions were considered equal to $15 \%$ of the total nitrogen used [17]; $\mathrm{CO}_{2}$ emissions were considered equal to $20 \%$ of the total urea used [23].

The data concerning the stages of extraction, semi-refining and esterification of the oil come from a French LCA study of Department for sustainable production and energy on biofuels [20] in which, however, sunflower oil is analysed; this compromise was necessary due to the lack of studies on the specific supply chain of bio-oil obtained from thistle. In addition, in this case, for taking into account the transportation phase, the distance from the farm to the oil transformation industry was estimated $(50 \mathrm{~km})$.

In the extraction phase, the main inputs involved were hexane, thermal energy and electricity, considering all the amounts necessary for one ton of oil extracted, while hexane was the main air emission [20]. For a ton of achenes, $250 \mathrm{~kg}$ of oil and $750 \mathrm{~kg}$ of cake were produced, with an oil yield of $25 \%$ [23]. In the semi-refining phase, the main inputs were phosphoric acid, sodium carbonate, thermal energy and electricity; the yield was $0.97 \mathrm{~kg}$ of refined oil for each $\mathrm{kg}$ of crude oil [20]. In the oil esterification phase the main inputs were hydrochloric acid, sodium methoxide, thermal energy and electricity, while emissions consisted of methanol in air and in water; the yield was $0.994 \mathrm{~kg}$ of esterified oil and $0.122 \mathrm{~kg}$ of glycerine for each $\mathrm{kg}$ of refined oil [20].

After obtaining the oil, the polyol synthesis phase was considered. Data were collected from [9] and refer to the synthesis of polyols from rapeseed oil, whose process is similar to the case under examination. The polyol was obtained by amidization process with diethanolamine (DEA); other necessary inputs included zinc acetate, inert gas and electricity. The study was carried out by means of a $50 \mathrm{~L}$ laboratory pilot reactor; therefore, the inputs could vary within a wider industrial process. Since zinc acetate was not present in the software database, the catalyst has been dissected into zinc oxide and acetic acid [9].

The data concerning the final phase of rigid polyurethane foam synthesis were collected from the Ecoinvent 3 database of the SimaPro software, referring to the synthesis process of a standard foam obtained from fossil resources, as the process does not vary with the use of vegetable polyols. The data that could vary is the foam yield of the vegetable polyol compared to the traditional one, but no studies have been found about it. The main inputs in this process 
are the polyol, diphenylmethane diisocyanate, pentane and electricity; emissions consist of pentane in air [17].

Finally, in the life cycle the process of converting thistle biomass into biogas and subsequent cogeneration was accounted for. Data related to this process were collected and adapted from the existing literature on biomass. The average percentage of dry matter within lignocellulosic biomass was considered to be about $40 \%$, while the percentage of volatile solids within dry matter was about $70 \%$ [25]; the biogas yield by lignocellulosic biomass is about 350 cubic meters per tonne of volatile solids, and the biogas calorific value is about $7350 \mathrm{kWh} /$ cubic meter having, in cogeneration, an average yield of $36 \%$ of electricity and $40 \%$ of thermal energy [26]. The amount of electricity and thermal energy necessary for converting biomass in biogas was taken from [26].

In reference to the allocation procedure, there are three by-products produced during the life cycle analysed: lignocellulosic biomass obtained from the cultivation phase, seed cake obtained from the oil extraction phase and glycerine obtained from the oil esterification phase. In our analysis, the use of biomass for energy production was assessed by means of a separate process, in which the impact connected with the production of electricity and heat was subtracted from the biomass production process. At this stage of the study, as regards to the other two by-products (i.e. seed cake and glycerine), is not yet considered a system expansion due to lack of information about their actual end usage on the considered system.

The following table (Table 1) shows the main inputs for the evaluation of the overall environmental impact in terms of natural resources, materials, energy, waste-flows, and main emissions subdivided in each single unit process.

TABLE 1. LCI WITH REFERENCE TO 1 TON OF RAW OIL

\begin{tabular}{llll}
\hline Cultivation Phase & & & \\
\hline Input & Unit & Amount & Data source/Comment \\
\hline Ploughing & $\mathrm{ha}$ & 0.17 & \\
Harrowing & $\mathrm{ha}$ & 0.33 & \\
Sowing & $\mathrm{ha}$ & 0.17 & \\
Urea & $\mathrm{kg} / \mathrm{ha}$ & 57.5 & \\
Diamonium phosphate $-\mathrm{N}$ & $\mathrm{kg} / \mathrm{ha}$ & 4.5 & \\
Diamonium phosphate $-\mathrm{P}$ & $\mathrm{kg} / \mathrm{ha}$ & 11.5 & Primary data from Novamont company \\
Compost & $\mathrm{kg} / \mathrm{ha}$ & 20 & \\
Fertilizing & $\mathrm{ha}$ & 1 & \\
Plant protection application & $\mathrm{ha}$ & 0.17 & \\
Pendimetalin & $\mathrm{g}$ & 151.7 & \\
Harvesting & $\mathrm{ha}$ & 1 & \\
Transport of materials & tkm & 2.33 & Hypothesis: 25 km from supplier \\
\hline Output & Unit & Amount & Data source/Comment \\
\hline Achenes & ton & 1.5 & Primary data from Novamont company \\
Lignocellulosic Biomass & ton & 15 & \\
\hline Emissions & Unit & Amount & Data source/Comment \\
\hline $\mathrm{N}_{2} \mathrm{O}$ & $\mathrm{kg} / \mathrm{ha}$ & 0.8358 & GNOC-JRC, 2014 [22] \\
$\mathrm{NH}_{3}$ & $\mathrm{~kg} / \mathrm{ha}$ & 9.3 & Ecoinvent [17] \\
$\mathrm{CO}_{2}$ & $\mathrm{~kg} / \mathrm{ha}$ & 11.5 & IPPC, 2006 [23] \\
\hline
\end{tabular}




\begin{tabular}{|c|c|c|c|}
\hline \multicolumn{4}{|l|}{ Oil Extraction } \\
\hline Input & Unit & Amount & Data source/comment \\
\hline Achenes & ton & 1 & DPED, 2010 [20] \\
\hline Hexane & $\mathrm{kg} /$ ton extracted oil & 2 & \\
\hline Electricity & $\mathrm{MJ} /$ ton extracted oil & 406 & \\
\hline Thermal energy & $\mathrm{MJ} /$ ton extracted oil & 1463 & \\
\hline Transport of achenes & $\mathrm{tkm}$ & 50 & Hypothesis: $50 \mathrm{~km}$ from farm \\
\hline Output & Unit & Amount & Data source/comment \\
\hline Raw oil & $\mathrm{kg}$ & 250 & Yield in oil 25\% (Curt et al., 2002) [24] \\
\hline Cake & $\mathrm{kg}$ & 750 & \\
\hline Emissions & Unit & Amount & Data source/comment \\
\hline Hexane & $\mathrm{kg} / \mathrm{ton}$ oil & 1.14 & DPED, 2010 [20] \\
\hline \multicolumn{4}{|l|}{ Oil refinement } \\
\hline Input & Unit & Amount & Data source/comment \\
\hline Raw oil & ton & 1 & DPED, 2010 [20] \\
\hline Phosphoric acid & $\mathrm{kg} /$ ton refined oil & 0.52 & \\
\hline Sodium carbonate & $\mathrm{kg} /$ ton refined oil & 2.07 & DPED, 2010 [20] \\
\hline Electricity & $\mathrm{MJ} /$ ton refined oil & 28 & \\
\hline Thermal energy & $\mathrm{MJ} /$ ton refined oil & 115 & \\
\hline Output & Unit & Amount & Data source/comment \\
\hline Refined oil & $\mathrm{kg} / \mathrm{kg}$ raw oil & 0.97 & DPED, 2010 [20] \\
\hline \multicolumn{4}{|l|}{ Oil esterification } \\
\hline Input & Unit & Amount & Data source/comment \\
\hline Refined oil & ton & 1 & \\
\hline Methanol & $\mathrm{kg} /$ ton esterified oil & 107.5 & \\
\hline hydrochloric acid & $\mathrm{kg} /$ ton esterified oil & 4 & \\
\hline sodium methoxide & $\mathrm{kg} /$ ton esterified oil & 5.3 & \\
\hline Electricity & $\mathrm{MJ} /$ ton esterified oil & 151 & \\
\hline Thermal energy & $\mathrm{MJ} /$ ton esterified oil & 1013 & DPED, 2010 [20] \\
\hline Output & Unit & Amount & Data source/comment \\
\hline Esterified oil & $\mathrm{kg} / \mathrm{kg}$ refined oil & 0.994 & \\
\hline Glycerine & $\mathrm{kg} / \mathrm{kg}$ refined oil & 0.122 & \\
\hline Emissions & Unit & Amount & \\
\hline Methanol in air & $\mathrm{kg} /$ ton esterified oil & 0.008 & \\
\hline Methanol in water & $\mathrm{kg} /$ ton esterified oil & 0.0232 & \\
\hline \multicolumn{4}{|l|}{ Polyol Synthesis } \\
\hline Input & Unit & Amount & Data source/comment \\
\hline Esterified oil & $\mathrm{kg}$ & 0.74 & \\
\hline Diethanolamine (DEA) & $\mathrm{kg}$ & 0.26 & \\
\hline Zinc acetate & $\mathrm{kg}$ & 0.0015 & \\
\hline Inert gas & g & 20.8 & Fridrihsone et al., 2020 [9] \\
\hline Electricity & $\mathrm{kWh}$ & 0.44 & \\
\hline
\end{tabular}




\begin{tabular}{llll}
\hline Output & Unit & Amount & \\
\hline Polyol & $\mathrm{kg}$ & 1 & \\
\hline Polyurethane Foam Synthesis & & & \\
\hline Input & Unit & Amount & Data source/comment \\
\hline Diphenylmethane diisocyanate & $\mathrm{kg}$ & 0.616 & \\
Pentane & $\mathrm{kg}$ & 0.054 & \\
Polyol & $\mathrm{kg}$ & 0.386 & \\
Electricity & $\mathrm{kWh}$ & 0.417 & Ecoinvent [17] \\
\hline Output & Unit & Amount & Data source/comment \\
\hline Rigid polyurethane foam & $\mathrm{kg}$ & 1 & \\
\hline Emissions & Unit & Amount & Data source/comment \\
\hline Pentane in air & $\mathrm{kg}$ & 0.003 & \\
\hline Biomass recovery & & & \\
\hline Input & Unit & Amount & Data source/comment \\
\hline Lignocellulosic biomass & ton & 15 & \\
Harvesting & $\mathrm{ha}$ & 1 & \\
Biomass transport & $\mathrm{tkm}$ & 750 & Hypothesis of $50 \mathrm{~km}$ from oil refinery \\
Electricity & $\mathrm{kWh/biomass} \mathrm{ton}$ & 12.8 & Bordoni et al., 2009 [26] \\
Thermal energy & $\mathrm{kWh/biomass} \mathrm{ton}$ & 48.7 & Bordoni et al., 2009 [26] \\
\hline Output & Unit & Amount & Data source/comment \\
\hline Electricity & $\mathrm{kWh}$ & 2646 & Maracchi, 2016 [25] \\
Thermal energy & $\mathrm{kWh}$ & 2940 & Bordoni et al., 2009 [26] \\
\hline & & &
\end{tabular}

\section{ReSUltS AND DisCUSSION}

\subsection{Life-Cycle Environmental Impact: Main Results}

Life Cycle Impact Assessment (LCIA) is a mandatory LCA step where potential environmental impacts throughout the product or process life cycle quantify the effect of the collected LCI data as in- and out-flows.

As mentioned, the LCIA was analysed using the approach proposed by the IMPACT 2002+ method as implemented in Simapro software [16]. The results are proposed to both mid- and end-point stage. However, the use of endpoint embeds a higher level of uncertainties due to the transformation to a single score output of the overall environmental performance (including normalization, grouping and weighting operations) although the results can be more easily addressed to potential decision makers

The overall impact at the characterization stage of the LCIA IMPACT2002+ is presented in Fig. 2. The main impact is attributable to the synthesis of the rigid polyurethane foam in almost all the impact categories mostly for global warming, non-renewable sources and respiratory disease by inorganic compounds (in the range of 73-90\%), except for the land use category that is associated with the field work. This impact is mainly in connection with the cumulative energy demand and use of chemicals during this stage (i.e. foam production). It is important to highlight the benefit on the avoided impact through the energy recovery from lignocellulosic leftovers from the harvesting phase. This provides for the terrestrial acidification an improvement of the environmental performances of $45 \%$. As well as from 
the perspective of the global warming decrease the benefit is evident reaching a value of $15 \%$ reduction.

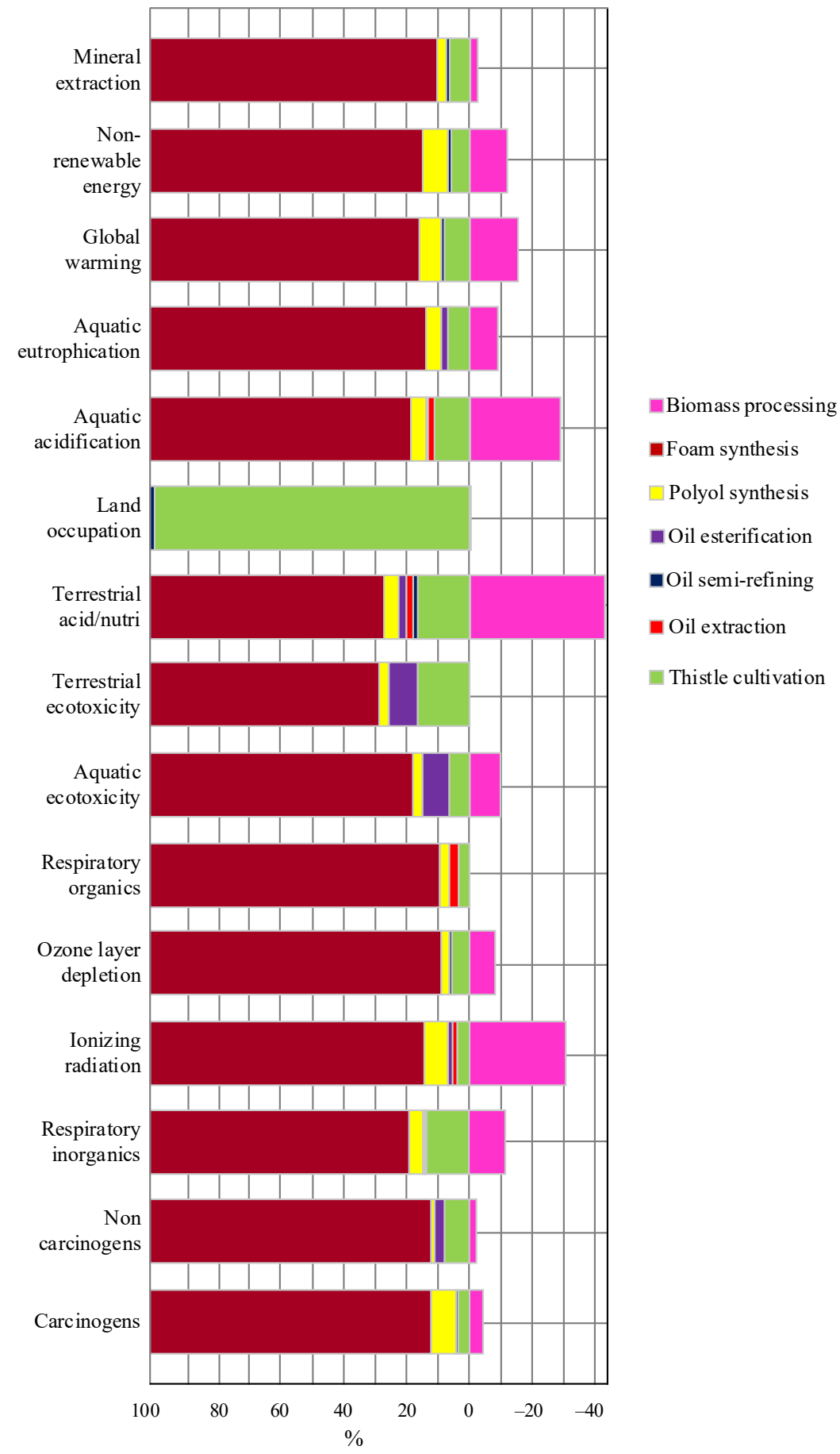

Fig. 2. IMPACT 2002+ midpoint impact categories for the production of $1 \mathrm{~kg}$ rigid polyurethane foam in percentage. 
It is important to show how GHG emissions as $\mathrm{CO}_{2 \text { eq }}$ are mainly allocated to the use of urea, as fertilizer responsible for $11 \mathrm{~kg} \mathrm{CO} 2 \mathrm{eq} /$ ha according to the IPCC factor, and to the fertilizers responsible for dinitrogen monoxide during fertilizer application (calculation according to Global Nitrous Oxides Calculator - GNOC [21]).

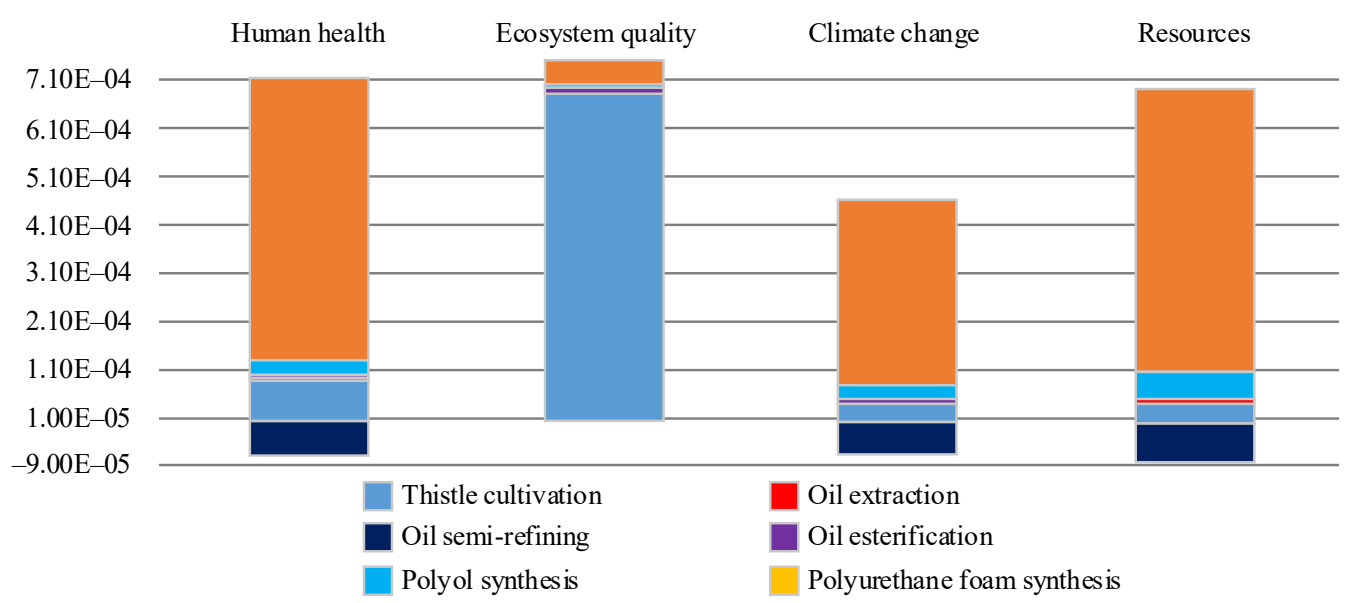

Fig. 3. IMPACT 2002+ normalized endpoint damage categories for the production of $1 \mathrm{~kg}$ rigid polyurethane foam.

Looking towards the results presented after the normalization (Fig. 3), Ecosystem quality and Human health are those impact categories with higher values. Land use is responsible for more than $90 \%$ of the overall impact in the Ecosystem quality. This represents an environmental hot spot, on which the conversion to cultivated land and the indirect land use change probably play relevant part. In fact, it was considered that the cultivation was not made on already existing agricultural land.

From the single score outputs presented at mid-point categories (Fig. 4) the use of nonrenewable energy sources together with land occupation, respiratory inorganics and global warming are those responsible for the whole major impact. More in specific, for use of nonrenewable energy sources, respiratory inorganics and global warming, a high contribution is given by the polyol extraction, probably due to the small scale of the considered pilot for which energy and fuels could heavily influence the effect on these impact categories.

In accordance with Fig. 5 it is possible to understand that the most impactful contribution is given from the synthesis of the rigid polyurethane foam, which also presents the higher impact for all the impact categories, except that one about the eco-system quality. In fact, this category is the higher for the cultivation phase and represents the second higher impact category. The contribution of oil treatment, oil refining and esterification are negligible compared to the rest of the life cycle.

The conversion of biomass to biogas and further use in a cogeneration unit (as avoided energy produced from natural gas) shows important benefits. In this study a sensitivity analysis has not been considered to evaluate the effect of a different avoided product. 


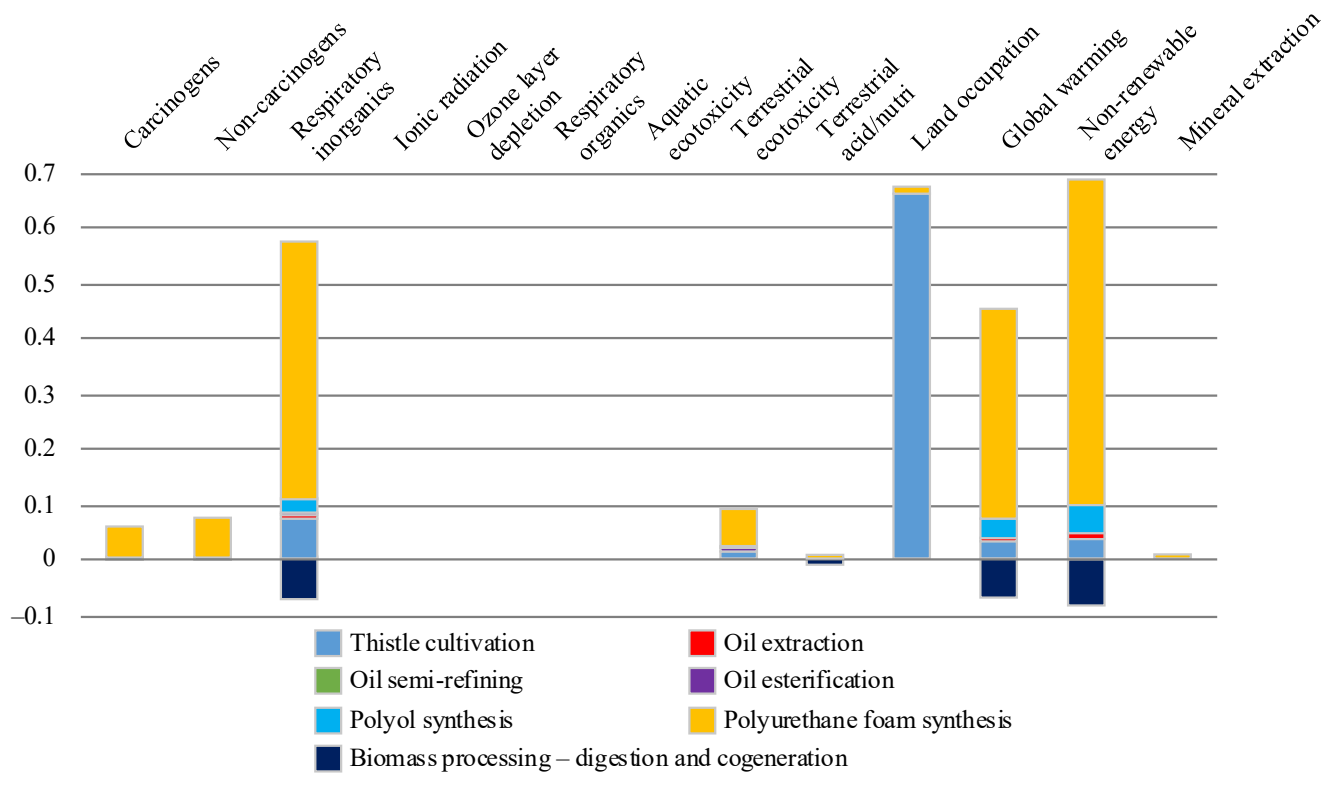

Fig. 4. IMPACT 2002+ midpoint impact categories for the production of $1 \mathrm{~kg}$ rigid polyurethane in $\mathrm{mPt}$.

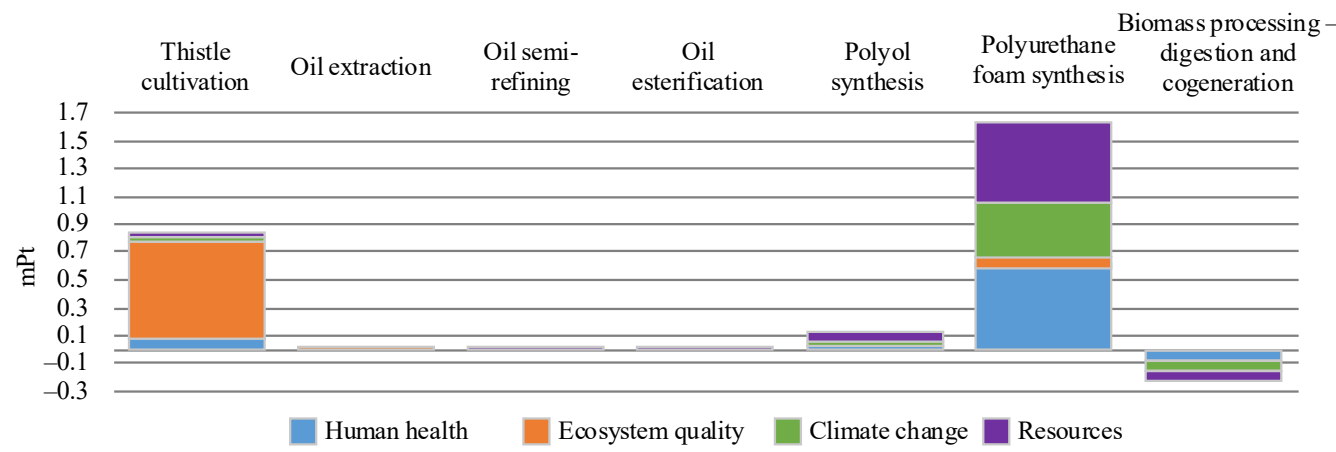

Fig. 5. IMPACT 2002+ environmental performances in ecological Point (mPt) for each steps of system for the production of $1 \mathrm{~kg}$ rigid polyurethane foam.

It can be noticed how the thistle cultivation is one of the most impactful category; this mainly because it is important to highlight how the land use impact categories has been considered not like a marginal land (due to a lack of this parameter in the selected database) in fact providing an overestimation of the impact.

At this stage of the study the use of the seed-cake from thistle oil extraction and glycerine from esterification process have not being considered as co-products.

\subsection{Sensitivity Analysis}

The sensitivity analysis had the aim of verifying the robustness of data and the influence of some of them on the overall result of the evaluation. In particular, two possible scenarios 
were analysed: the variation in the grain yield of the thistle; the variation in electricity consumption in the polyol synthesis phase.

The hypothesis of variation of the yield arises from the uncertainty of the environmental and climatic conditions, as the thistle yields can considerably increase in proportion to the greater water reserves in the soil. Four variations of yield were considered: $-15 \%,-5 \%$, $+5 \%$ and $+15 \%$.

The hypothesis of variation of the electricity consumption was considered because the data collected on the polyol synthesis refer to experimentation conducted in a $50 \mathrm{~L}$ pilot reactor, while industrial production takes place on a much larger scale, with a lower electricity consumption. Two reduction thresholds were considered: $-20 \%$ and $-40 \%$.

Fig. 6 reports the trend of sensitivity analysis related to yield variation. The results of the analysis show that the sensitivity ratio, defined as the ratio between the percentage change in the output data and the percentage change in the input data, reaches a maximum value of 0.42 . This indicates that the overall environmental impact of the system varies less than proportionally with respect to the variation in grain yield; it implies that the model is not sensitive to this input data. An interesting feature is that the system is more sensitive to a significant drop in yield than to a significant increase in the same; in fact, a $15 \%$ increase in yield corresponds to a $4.6 \%$ reduction in environmental impact while a $15 \%$ decrease in yield corresponds to a $6.25 \%$ increase in environmental impact.

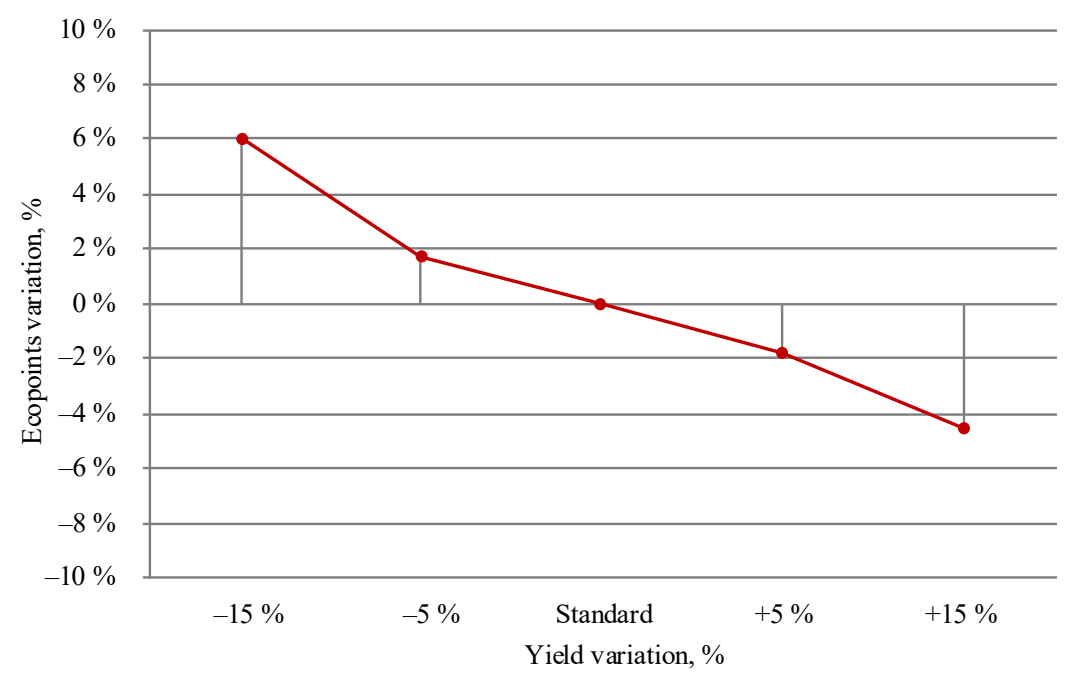

Fig. 6. Sensitivity analysis graph relating to the variation thistle seed yield.

Fig. 7 shows the trend of sensitivity analysis for electricity consumption. In this case, the sensitivity ratio, constant for both thresholds, is very low, having a value of 0.021 . This shows that the system is not sensitive to the variation in electricity consumption in the polyol synthesis phase. 


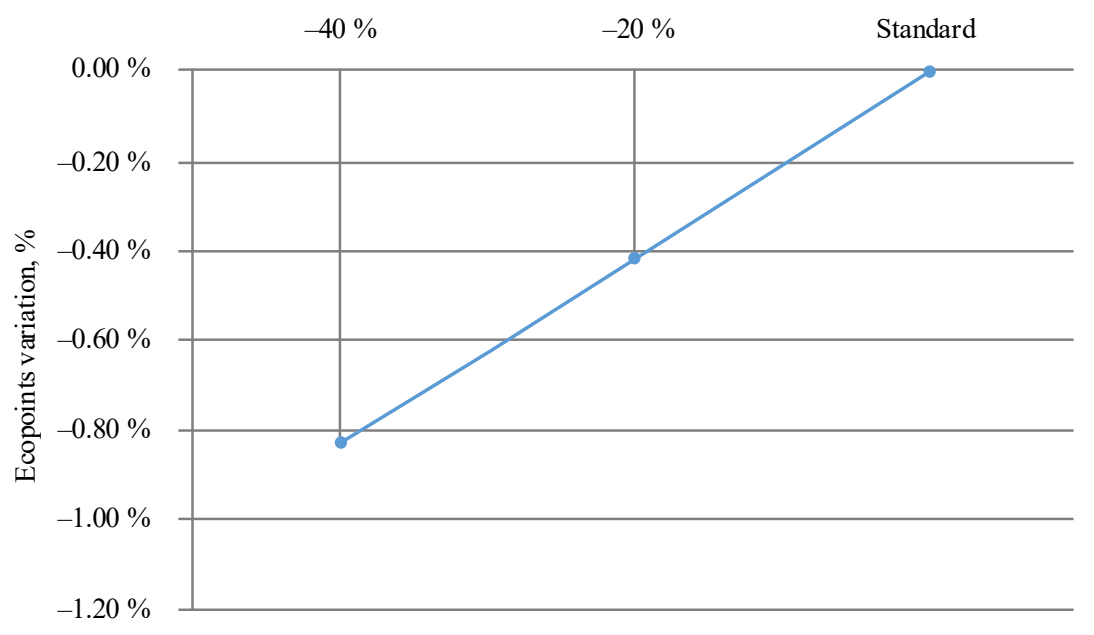

Electrical consumption variation, $\%$

Fig. 7. Sensitivity analysis graph relating to the variation of the electrical consumption.

The greater sensitivity of the system towards the change in grain yield confirms that the cultivation phase has a greater impact than the oil treatment phases; despite this, the sensitivity ratio always remains less than 1 , as the greatest contribution to the overall impact of the system is given by the synthesis phase of the polyurethane foam, which was not affected by the sensitivity analysis.

\section{Conclusions}

This work aimed to analyse the environmental assessment of a hypothetical production chain of rigid polyurethane foam obtained from thistle seed, following and integrating the path already tracked, in a partial way, by other studies. The LCA methodology was used in this case study.

The main difficulties encountered concerned the complexity of the data collection phase, which is a basic aspect for a robust LCA analysis, due to the lack of previous work regarding the evaluation of the entire chain of bioplastics deriving from thistle seed oil. However, the definition of some hypotheses and assumptions allowed us to perform the analysis from which interesting results have been obtained.

Our results showed that the production of the polyurethane foam was the most impacting phase in the analysed system. The entire production process of the vegetable polyol had a lower overall impact than the aforementioned phase.

Within the production process of the polyol, the cultivation phase was the most affecting. However, it is important to note that the software did not allow to consider the use of marginal land as input parameter, and this inevitably led to an overestimation of the impacts.

It must be highlighted that within a further development of the study should be included the boundaries extension including the avoided impact from the use of the seed cake and glycerine.

Furthermore, these results should be read in a broader sustainability perspective that includes the social sphere in addition to the environmental one; in fact, the cultivation of this 
crop on marginal lands could represent an added value for these areas, otherwise left uncultivated due to their unfavourable conditions. In addition, an important aspect concerns the avoided impact resulted by all the by-products, which can be used in other supply chains reducing the overall environmental load of the entire system; this aspect, in this study, is visible in the positive effects of the conversion process of lignocellulosic biomass.

Our analysis was not comparative and did not intend to make a comparison between products obtained from fossil resources and analogous bio based products. Rather, it aimed at assessing the environmental load generated by the system investigated, identifying the most impacting phases and potential strengths deriving from the cultivation of species in marginal lands with low input requirements, in an optic of development of large bio-based supply chains, in which the recovery of all the products and by-products obtained takes place.

Furthermore, the issues of sustainability and environmental assessments have always been considered very complex, including a multiplicity of aspects; for this reason, it is often necessary to analyse the different situations case-by-case and depending from the context; consequently, this assessment must be considered as a starting point for other future works in the field of polymers of vegetable origin.

\section{ACKNOWLEDGEMENT}

This study was partly funded by the FORTE project (2014-2020 Umbrian Rural Development Programme- sub-measure 16.1), co-funded by the European Agricultural Fund for Rural Development (EAFRD).

\section{REFERENCES}

[1] Patermann C., Aguilar A. The origins of the bioeconomy in the European Union. New Biotechnology 2018:40(A):20 24. https://doi.org/10.1016/j.nbt.2017.04.002

[2] Xanthos D., Walker T. R. International policies to reduce plastic marine pollution from single-use plastics (plastic bags and microbeads): A review. Marine Pollution Bulletin 2017:118(1-2):17-26. https://doi.org/10.1016/j.marpolbul.2017.02.048

[3] Álvarez-Chávez C. R., et al. Sustainability of bio-based plastics: general comparative analysis and recommendations for improvement. Journal of Cleaner Production 2012:23(1):47-56. https://doi.org/10.1016/j.jclepro.2011.10.003

[4] Huber G. W., Iborra S., Corma A. Synthesis of Transportation Fuels from Biomass: Chemistry, Catalysts, and Engineering. Chemical Reviews 2006:106(9):4044 4098. https://doi.org/10.1021/cr068360d

[5] Van De Mark M. R., Sandefur K. Vegetable oils in paint and coatings. Industrial Uses of Vegetable Oil. Illinois: AOCS Press, 2005:143-162.

[6] Sawpan M. A. Polyurethanes from vegetable oils and applications: a review. Journal of Polymer Research 2018:25:184. https://doi.org/10.1007/s10965-018-1578-3

[7] Garrison T. F., Kessler M. R. 3-Plant Oil-Based Polyurethanes. Bio-Based Plant Oil Polymers and Composites 2016:37-54. https://doi.org/10.1016/B978-0-323-35833-0.00003-7

[8] Tan S., et al. Rigid polyurethane foams from a soybean oil-based polyol. Polymer 2011:52(13):2840-2846. https://doi.org/10.1016/j.polymer.2011.04.040

[9] Fridrihsone A., et al. U. Life Cycle Assessment of Vegetable oil based polyols for polyurethane production. Journal of Cleaner Production 2020:266. https://doi.org/10.1016/j.jclepro.2020.121403

[10] Mubofu E. B. Castor oil as a potential renewable resource for the production of functional materials. Sustainable Chemical Process 2016:4:11. https://doi.org/10.1186/s40508-016-0055-8

[11] Queirós J., Malça J., Freire F. Environmental life-cycle assessment of rapeseed produced in Central Europe: addressing alternative fertilization and management practices. Journal of Cleaner Production 2015:99:266-274. https://doi.org/10.1016/j.jclepro.2015.03.016

[12] Sanz Requena J. F., et al. Life Cycle Assessment (LCA) of the biofuel production process from sunflower oil, rapeseed oil and soybean oil. Fuel Processing Technology 2011:92:190-199. https://doi.org/10.1016/j.fuproc.2010.03.004

[13] Fernández J., García Muller M. Sistema de separación fraccionada de la biomasa integral de cardo, Cynara cardunculus (Fractional separation system for the integral biomass of thistle, Cynara cardunculus.). Madrid: Istituto di Madrid di ricerca agraria, Università Politecnica di Madrid, 2004:11. (in Italian) 
[14] ISO. ISO 14044: Environmental Management-Life Cycle Assessment-Requirements and Guidelines. ed. vol.: ISO. 2006.

[15] ISO. ISO 14040: Environmental management-Life cycle assessment-Principles and framework., ed. vol.: ISO. 2006.

[16] Goedkoop M., et al. Introduction to LCA with SimaPro. San Francisco: Pre, 2016.

[17] Wernet G., et al. The ecoinvent database version 3 (part I): overview and methodology. The International Journal of Life Cycle Assessment 2016:21(9):1218-1230 https://doi.org/10.1007/s11367-016-1087-8

[18] Jolliet O., et al. IMPACT 2002+: A new life cycle impact assessment methodology. The International Journal of Life Cycle Assessment 2003:8:324 https://doi.org/10.1007/BF02978505

[19] FORTE project, Filiera delle Oleaginose a Recupero Total, [06.11.2020] http://www.goforte.it/

[20] Department for sustainable production and energy (DPED) - ADEME. Analyses de Cycle de Vie appliquées aux biocarburants de première génération consommés en France (Life Cycle Analyzes applied to first generation biofuels consumed in France.). ANNEX Report final. DPED, 2010. (in French)

[21] IVPU. Life Cycle Assessment of PUR rigid foam thermal insulation materials - Energy Consumption and Energy Saving. Stuttgart, 2002.

[22] Köble R. JRC Technical Reports. The Global Nitrous Oxide Calculator - GNOC - Online Tool Manual Version 1.2.4. 27-May-2014. European Commission: Publications Office of the European Union, 2013.

[23] IPCC. Guidelines for National Greenhouse Gas Inventories. Geneva: IPCC, 2006.

[24] Curt M. D., Sanchez G., Fernandez J. The potential of Cynara cardunculus L. for seed oil production in a perennial cultivation system. Biomass Bioenergy 2002:23(1):33-46. https://doi.org/10.1016/S0961-9534(02)00030-2

[25] Maracchi G. Le biomasse lignocellulosiche (Lignocellulosic biomasses.). Firenze: Firenze University Press, 2016. https://doi.org/10.36253/978-88-6655-985-6 (in Italian)

[26] Bordoni A., et al. La filiera del biogas. Aspetti salienti dello stato dell'arte e prospettive (The biogas supply chain. Salient aspects of the state of the art and perspectives.). Osimo Stazione: ASAAM, 2009. (in Italian). 